\title{
Cholecystectomy after breast reconstruction with a pedicled autologous tram flap. Types of surgical access
}

\author{
Magdalena Graczyk¹, Justyna Kostro², Jerzy Jankau, Justyna Bigda², Andrzej Skorek ${ }^{1}$ \\ ${ }^{1}$ Department of Plastic Surgery, Medical University of Gdansk, Gdansk, Poland \\ ${ }^{2}$ Department of General, Endocrine and Transplant Surgery, Medical University of Gdansk, Gdansk, Poland
}

Videosurgery Miniinv 2014; 9 (3): 473-478

DOI: $10.5114 /$ wiitm.2014.43081

\begin{abstract}
The number of breast reconstruction procedures has been increasing in recent years. One of the suggested treatment methods is breast reconstruction with a pedicled skin and muscle TRAM flap (transverse rectus abdominis muscleTRAM). Surgical incisions performed during a cholecystectomy procedure may be located in the areas significant for flap survival. The aim of this paper is to present anatomical changes in abdominal walls secondary to pedicled skin and muscle (TRAM) flap breast reconstruction, which influence the planned access in cholecystectomy procedures. The authors present 2 cases of cholecystectomy performed due to cholelithiasis in female patients with a history of TRAM flap breast reconstruction procedures. The first patient underwent a traditional method of surgery 14 days after the reconstruction due to acute cholecystitis. The second patient underwent a laparoscopy due to cholelithiasis 7 years after the TRAM procedure. In both cases an abdominal ultrasound scan was performed prior to the operation, and surgical access was determined following consultation with a plastic surgeon. The patient who had undergone traditional cholecystectomy developed an infection of the postoperative wound. The wound was treated with antibiotics, vacuum therapy and skin grafting. After 7 weeks complete postoperative wound healing and correct healing of the TRAM flap were achieved. The patient who had undergone laparoscopy was discharged home on the second postoperative day without any complications. In order to plan a safe surgical access, it is necessary to know the changes in the anatomy of abdominal walls following a pedicled TRAM flap breast reconstruction procedure.
\end{abstract}

Key words: laparoscopic cholecystectomy, transverse rectus abdominis muscle flap, cholecystitis, breast reconstruction procedures, natural orifice transluminal endoscopic surgery.

\section{Introduction}

Breast cancer is the most frequently occurring malignant carcinoma in women, and it also has an increasing number of new cases [1]. Medical advances and considerable public awareness are the factors behind a growing number of women who decide to have a breast-saving procedure or breast reconstruction surgery. A breast may be reconstructed with autologous tissue - TRAM flap (transverse rectus abdominis muscle - TRAM), LD flap (latissi- mus dorsi muscle - LD), by means of microvascular anastomosis, or with the use of a silicon implant, or a combination of LD flap and implant methods. In TRAM reconstruction, the flap pedicle comprises the rectus abdominis muscle with inferior epigastric vessels, elevated together with a skin-adipose island (Figure 1). In most cases, due to the extent of lost tissue and patient's body composition, it is necessary to use a mesh to prevent postoperative hernia development [2]. The changes in the anatomy of abdominal walls following TRAM breast reconstruction

\section{Address for correspondence}

Magdalena Graczyk MD, Department of Plastic Surgery, Medical University of Gdansk, 17 Mariana Smoluchowskiego St, 80-214 Gdansk, Poland, phone/fax: +48 605548 958, e-mail: m.a.graczyk@gmail.com 


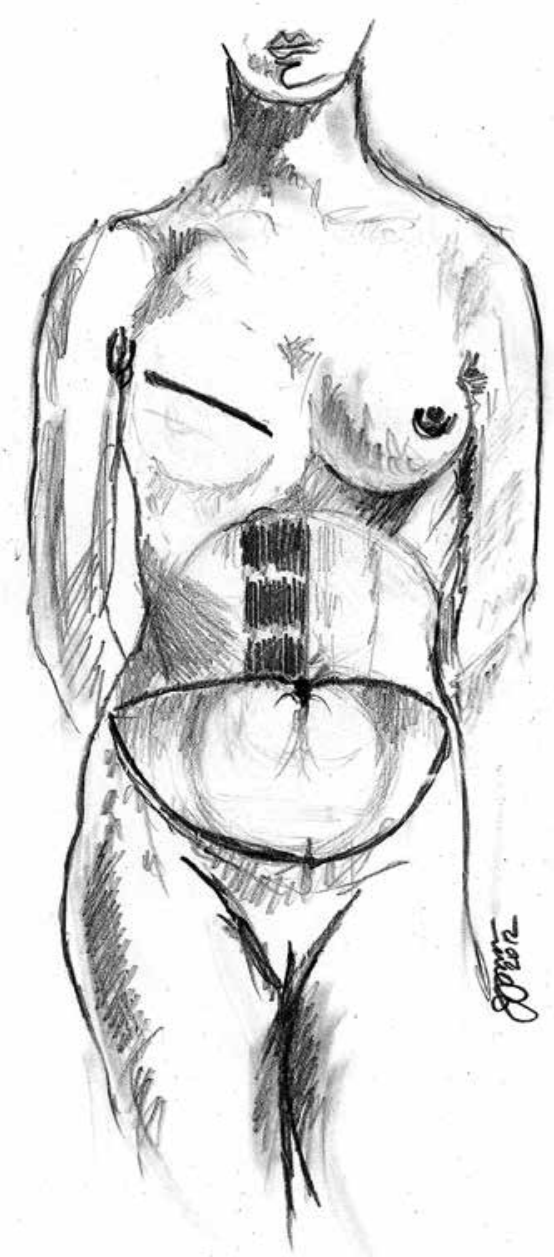

Figure 1. TRAM flap breast reconstruction model

may lead to complications and, consequently, subsequent surgical procedures (Figure 2).

Symptomatic cholelithiasis is an indication for cholecystectomy. Following other operations, the condition may exacerbate or cholecystitis may develop. In 1884 Duncan reported a case of acute acalculous cholecystitis (AAC) which occurred in a patient 2 days after a femoral hernia repair [3]. Thompson and Inoue described a number of AAC cases which developed in patients who had undergone operations for other indications [4, 5]. The gold standard for cholecystectomy is a laparoscopic procedure; however, some cases necessitate the traditional method of operation [6-9]. Now we have a few possibilities of gallbladder removal: open cholecystectomy, multiport laparoscopic cholecystectomy, single inci-

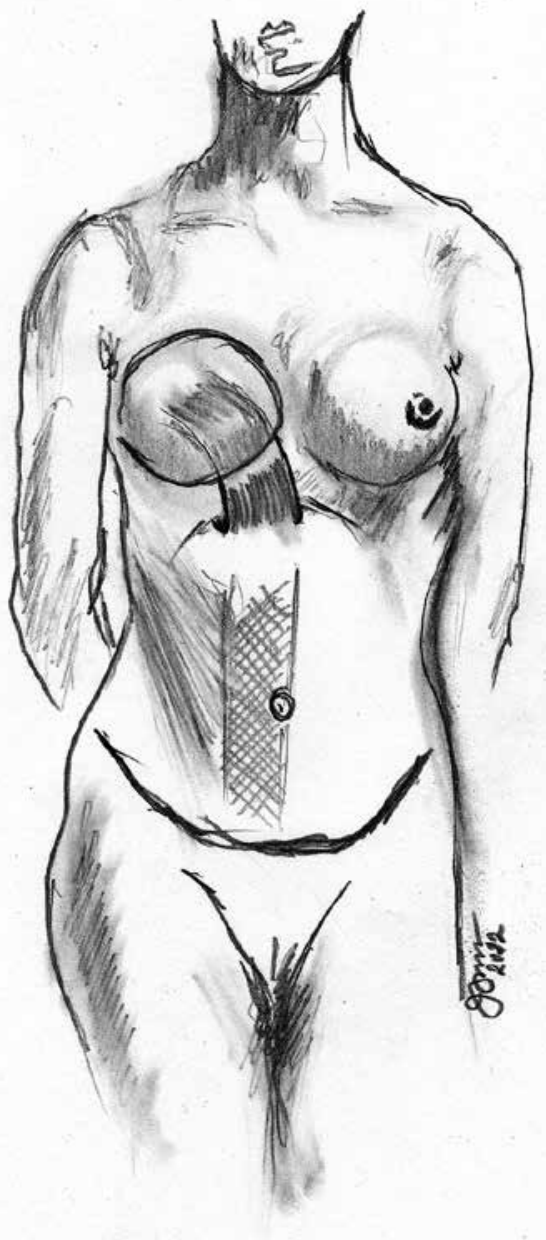

Figure 2. Changes in the anatomy of abdominal walls following a TRAM flap breast reconstruction procedure

sion laparoscopic surgery (SILS) and natural orifice transluminal endoscopic surgery (NOTES) [10, 11]. Postoperative complications can be a consequence of each of them.

This paper presents the cases of 2 patients who were operated on due to cholelithiasis in different periods after a pedicled TRAM flap breast reconstructive procedure. In case A the traditional method was used, and laparoscopy was used in case B.

\section{Case reports}

\section{Case I}

A female patient aged 45 , diagnosed with mammary ductal carcinoma (DCIS stage 1 and stage 2), underwent right-side mastectomy followed by che- 
motherapy and radiotherapy. Two years after mastectomy, the patient was qualified as eligible and underwent pedicled IPSI TRAM flap (ipsilateral transverse rectus abdominis muscle flap) breast reconstruction with the use of a hernia mesh. The postoperative period did not include complications and the patient was discharged home on day 7 after the procedure in a good general status. A week after discharge, the patient returned to the department with severe pain in the right epigastric region, nausea and emesis, which she had had for the past 2 days. The laboratory tests indicated leukocytosis $19.74 \mathrm{G} / \mathrm{l}$, C-reactive protein (CPR) $109.87 \mathrm{mg} / \mathrm{l}$, elevated $\gamma$-glutamyl transferase activity $68 \mathrm{U} / \mathrm{l}$ and alkaline phosphatase activity $184 \mathrm{U} / \mathrm{l}$, and bilirubin < $1.6 \mathrm{mg} / \mathrm{dl}$. Abdominal ultrasound scan revealed enlargement of the gallbladder with wall thickening; the gallbladder was partly filled with semiliquid contents, with small concrements. Other abdominal organs appeared normal. The TRAM flap had normal blood supply and unobstructed blood vessels in the pedicle. Due to acute cholecystitis the patient was qualified for an urgent laparoscopic cholecystectomy. The patient received preventive antibiotic therapy with metronidazole and amoxicillin with clavulanic acid. During an ultrasound scan, following consultation with a plastic surgeon, the TRAM flap pedicle was identified and marked, and the location of trocars and an incision line in case of potential method conversion was determined. The optical trocar was placed $2 \mathrm{~cm}$ to the left of the navel. The main working trocar was placed to the right and inferiorly to the pedicle and passed through the hernia mesh, approximately $8 \mathrm{~cm}$ inferiorly to the xiphoid process. Two trocars were placed $2 \mathrm{~cm}$ inferiorly to the costal arch bilaterally to the midclavicular line. For technical reasons, it was necessary to change the surgical access to the "open method" during the operation. The abdominal cavity was opened with Kocher's incision, $10 \mathrm{~cm}$ long, below the pedicle, through the hernia mesh, connecting the trocar punctures. The gallbladder with inflammatory abnormalities was resected. In the postoperative period a wound infection complication developed. Following vacuum therapy (two 5-day cycles), targeted antibiotic therapy (tigecycline applied for 14 days) and split-thickness skin grafting on day 48 of the cholecystectomy procedure the wounds were completely healed. The histopathological examination of a sample revealed acute phlegmonous cholecystitis with ulcers of the gallbladder.

\section{Case II}

A female patient aged 65 , diagnosed with ductal carcinoma of the left breast, treated with neoadjuvant chemotherapy, underwent left-side mastectomy with simultaneous IPSI TRAM reconstruction followed by radiotherapy. Four years after the reconstruction procedure the patient was operated on due to abdominal hernia at the site of the harvested muscle. The hernia repair procedure involved the use of hernia mesh. The postoperative period did not include complications. Eight years after the reconstruction procedure, chronic cholecystitis was diagnosed. Laboratory tests (blood count and electrolyte panel) yielded normal findings. Abdominal ultrasound scan revealed signs of chronic cholecystitis - a thickened gallbladder wall. Other abdominal organs appeared normal. The TRAM flap received a normal blood supply, and the blood vessels in the pedicle were unobstructed. Due to symptomatic cholelithiasis the patient was qualified for an elective laparoscopic cholecystectomy. The patient received preventive antibiotic therapy with metronidazole and amoxicillin with clavulanic acid. Location of trocars and an incision line in the event of potential need for method conversion were established as above. The optical trocar was placed $2 \mathrm{~cm}$ to the right of the navel. The main working trocar was placed to the right and inferiorly to the pedicle and passed through the hernia mesh, about $8 \mathrm{~cm}$ inferiorly to the xiphoid process. Two subsequent trocars were placed $2 \mathrm{~cm}$ inferiorly to the costal arch bilaterally to the midclavicular line. The isolation and clipping of the cystic duct and cystic artery were followed by subserosal removal of the gallbladder. The postoperative course was uneventful. The patient was discharged home on day 2 . The histopathological examination of a sample revealed chronic cholecystitis, muscular hyperplasia of the gallbladder.

\section{Discussion}

Breast reconstruction with a TRAM flap - abdominis rectus muscle with a skin-adipose island - was first presented by Hartrampf et al. [12] in 1982 and since then has become the gold standard for breast reconstruction. The advances in microsurgical techniques have led to a decrease in the use of this method. The traditional TRAM flap with a superior pedicle involves a skin-adipose island from the lower abdomen and abdominis rectus muscle, while blood supply 


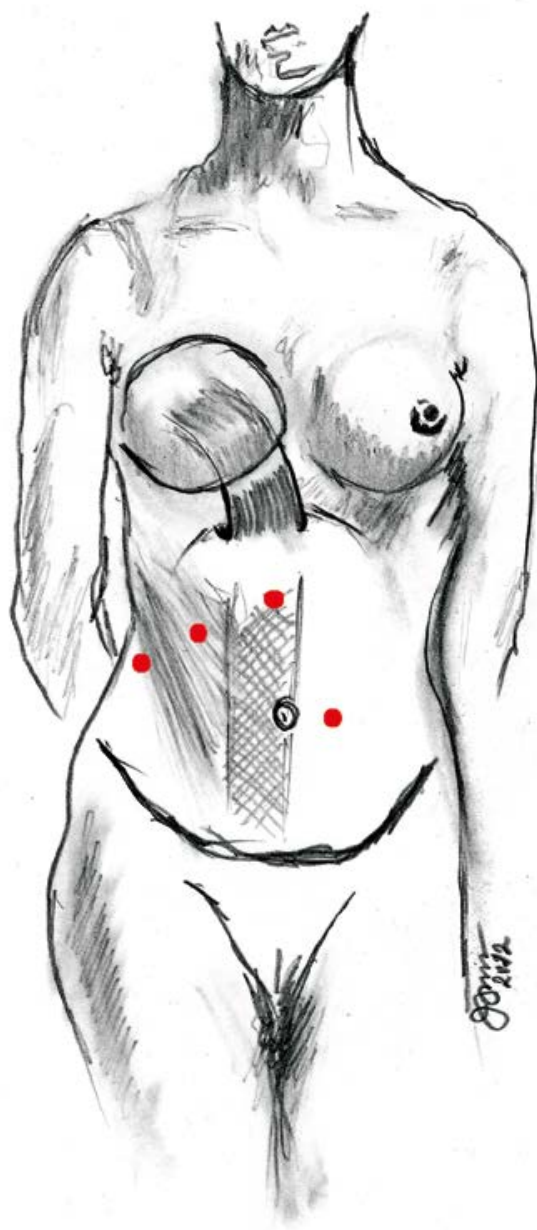

Figure 3. Placement of trocars with regard to post-reconstruction anatomical changes

is based on the superior epigastric vessels (Figure 1). The flap with the muscle is transferred through a subcutaneous tunnel, which passes laterally to the xiphoid process to the mastectomy site [13]. In order to close the site of insertion after the abdominis rectus muscle has been transferred, a mesh is used to prevent hernia or bulging after autologous tissue breast reconstruction [14-18]. The presence of the mesh does not affect trocar or incision line placement [19-22]. Muller, however, indicates that it is necessary to thoroughly suture the hernia mesh if tissue loss is more than $5 \mathrm{~mm}$ [22]. The use of synthetic material carries an increased risk of a surgical site infection - from $6 \%$ to $10 \%[19,20]$; it is, therefore, advisable to extend preventive antibiotic treatment in subsequent operations. In rare cases muscle rims are sutured directly. After a few weeks the produced collagen should reinforce the sutures well enough to withstand up to $12 \mathrm{~mm} \mathrm{Hg}$ pressure of the generated pneumoperitoneum, which is necessary in a laparoscopic procedure $[10,11,19]$. In these cases, special care must be taken during laparoscopic cholecystectomy performed within a short period of time after the reconstruction surgery. What is more, reduced elasticity of the abdominal wall tissues may adversely affect the visibility of the operative site [20]. When abdominal walls are closed after a TRAM flap reconstruction procedure, a minor lateral displacement of the navel on the autologous pedicle may be occasionally observed [23]. It mainly applies to cases of the primary closure, when tissues are transferred to the site of the abdominis rectus muscle. That is why the optical trocar should be inserted very carefully, preferably laterally to the navel, in the opposite direction to the side which was previously operated on, thanks to which the suture line of the rectus muscle sheath closure can be bypassed. If the navel pedicle is damaged, it develops necrosis, in which case it needs to be resected and, subsequently, reconstructed [21]. The TRAM flap may be based on the superior epigastric vessels located ipsilaterally to the reconstructed breast (IPSI TRAM), contralaterally (TRAM CONTRA - contralateral transverse rectus abdominis muscle flap) or bilaterally (bipedicled TRAM). If bilateral mastectomy is necessary, a bilateral TRAM flap procedure may be performed using both abdominis rectus muscles. Superior epigastric vessels, which constitute blood supply to the TRAM flap, usually travel approximately $1 \mathrm{~cm}$ laterally to the inferior sternal edge, with variation in $10 \%$ of cases [24], and at the time of reconstruction, the pedicle is additionally twisted. During the laparoscopic procedures placing the operating trocar inferiorly to the xiphoid process should depend on the location of the pedicle. An exact description of the breast reconstruction surgery or the use of Doppler ultrasound examination seems to be advisable in order to determine and mark the pedicle (Figure 3). It is especially important if a short period of time has elapsed since the reconstruction procedure, as its potential consequences include flap necrosis. Laparoscopic surgery with a correctly determined trocar location appears to be safer than traditional methods. It should be noted that harvesting the abdominis rectus muscle along with a skin island involves dissecting abdominal walls from the pubic symphysis to the costal margin. Kocher's incision 
performed within a short time of the reconstruction leads to ischemia of skin and the underlying subcutaneous tissue. Therefore, incision length should be restricted to a minimum. Sen et al. [25] advocate simultaneous traditional cholecystectomy with TRAM flap breast reconstruction if both operations are elective procedures in a given patient. In such cases, what should rather be considered is laparoscopic cholecystectomy, which is the procedure of choice in cases of symptomatic cholelithiasis, before the planned breast reconstruction. In addition, simultaneous procedures associated with a large operating field may increase the risk of infection caused by Clostridium sp., which is the etiological factor of cholangitis in $7 \%$ of cases [26].

Nowadays we also observe a great interest in and the development of new miniinvasive operations [27]. Natural orifice transluminal endoscopic surgery is controversial and also maybe the most intriguing new technique. It should be noted that cholecystectomy performed by this method would avoid many of the complications associated with a flap such as the blood supply or infection.

We should be looking for new opportunities for gallbladder operation but the method of choice should be the best and safe for the patients.

\section{Conclusions}

The awareness of anatomical differences which develop secondary to reconstructive procedures is a prerequisite for planning a safe surgical access in cholelithiasis cases. The unfamiliarity of anatomical differences may lead to pedicle damage, and, consequently, flap loss, navel loss, hindered wound healing or abdominal wall necrosis, which was observed in the case described above. Laparoscopic cholecystectomy should be the method of choice in patients with a history of pedicled TRAM flap breast reconstruction. In cases of symptomatic cholelithiasis, an elective LC prior to breast reconstruction seems to be a sound solution.

\section{References}

1. http://epid.coi.waw.pl/krn/

2. Bucky LP, May JW Jr. Synthetic mesh. Its use in abdominal wall reconstruction after the TRAM. Clin Plast Surg 1994; 21: 273-7.

3. Glenn F. Acute cholecystitis following the surgical treatment of unrelated disease. Ann Surg 1947; 126: 411-20.

4. Thompson JW 3rd, FerrisS DO, Baggenstoss AH. Acute cholecys titis complicating operation for other diseases. Ann Surg 1962; 155: 489-94.
5. Inoue T, Mishima Y. Postoperative acute cholecystitis: a collective review of 494 cases in Japan. Jpn J Surg 1988; 18: 35-42.

6. Bielecki K, Kozicki I. Biliary tract surgery. In: Principles of surgery [Polish]. Szmidt J, Kużdżała J, Gruca Z, et al. (eds.). Wydawnictwo Medycyna Praktyczna, Krakow 2010.

7. Michalik M, Frask A, Trybull A, et al. Methods of treatment for gallbladder diseases. Videosurgery Miniinv 2009; 4: 121-5.

8. Bierca J, Kowalski B, Kosim A, et al. Lethal, iatrogenic complications of laparoscopic cholecystectomy. Videosurgery Miniinv 2006; 1: 10-2.

9. Bitner M, Jaszewski R, Jander S, Maciejewski M. Laparoscopic cholecystectomy delayed by complicated myocardial infarction with papillary muscle rupture, and performed after unique complex mitral repair. Videosurgery Miniinv 2013; 8: 170-3.

10. Wirkowski A, Pesta W. Pitfalls of laparoscopic cholecystectomy - own experience [Polish]. Videosurgery Miniinv 2008; 3 : 179-85.

11. Kurpiewski W, Pesta W, Kowalczyk M, et al. The outcomes of SILS cholecystectomy in comparison with classic four-trocar laparoscopic cholecystectomy. Videosurgery Miniinv 2012; 7: 286-93.

12. Hartrampf CR, Scheflan M, Black PW. Breast reconstruction with a transverse abdominal island flap. Plast Reconstr Surg 1982; 69: 216-25.

13. Kołodziejski LS, Towpik E. Breast surgery. In: Principles of surgery [Polish]. Szmidt J, Kużdżała J, Gruca Z, et al. (eds.). Wydawnictwo Medycyna Praktyczna, Krakow 2010.

14. Crosby MA, Adams WP Jr. Mesh in aesthetic and reconstructive surgery. Roundtables in Plastic Surgery 2005; 3: 3-51.

15. Beasley ME. The pedicled TRAM as preference for immediate autogenous tissue breast reconstruction. Clin Plast Surg 1994; 21: 191-205.

16. Moscona RA, Ramon Y, Toledano H, Barzilay G. Use of synthetic mesh for the entire abdominal wall after TRAM flap transfer. Plast Reconstr Surg 1998; 101: 706-10.

17. Kroll SS, Marchi M. Comparison of strategies for preventing abdominal-wall weakness after TRAM flap breast reconstruction. Plast Reconstr Surg 1992; 89: 1045-51.

18. Nahai F. Comparison of strategies for preventing abdominal-wall weakness after TRAM flap breast reconstruction. Plast Reconstr Surg 1992; 89: 1052-3.

19. Williams JK, Bostwick J 3rd, Daneker G, Fink A. Laparoscopic cholecystectomy following autogenous breast reconstruction with a TRAM flap. Surg Endosc 1995; 9: 719-23.

20. Awtrey CS, Abu-Rustum NR, Disa JJ, et al. Laparoscopic bilateral salpingo-oophorectomy in breast cancer patients after transverse rectus abdominus myocutaneous flap reconstructive surgery. Gynecol Oncol 2005; 99: 720-5.

21. Ghavami B, Maillard GF, Grutter P, Cech P. Laparoscopic cholecystectomy through prolene mesh after bilateral TRAM flap. Plast Reconstr Surg 1997; 99: 2103-5.

22. Muller CY, Coleman RL, Adams WP Jr. Laparoscopy in patients following transverse rectus abdominis myocutaneous flap reconstruction. Obstet Gynecol 2000; 96: 132-5.

23. Schoeller T, Wechselberger G, Otto A, et al. New technique for scarless umbilical reinsertion in abdominoplasty procedures. Plast Reconstr Surg 1998; 102: 1720-3. 
24. Bostwick J. Abdominal flap reconstruction. In: Plastic and reconstructive breast surgery. 2nd ed. St Louis, Mo: Quality Medical Publishing Inc; 2000; 981-1146.

25. Sen M, Inan A, Yenidünya MO. Concomitant open cholecystectomy and mammary reconstruction with bipedicled TRAM flap. Plast Reconstr Surg 2004; 113: 1087-8.

26. Gilbert DN, Moellering RC, Eliopoulos GM, et al. The Sanford Guide to Antimicrobial Therapy 2011; Kraków 2011.

27. Kobiela J, Stefaniak T, Laski D, et al. NOTES. Study on patients' perspective. Videosurgery Miniinv 2013; 8: 232-7.

Received: 22.10.2013, accepted: 17.02.2014. 